\title{
IMPLEMENTATION PRINCIPLES OF THE PROJECT MANAGEMENT BY A SECURITY SYSTEMS DESIGN
}

The project management includes a complicated complex of activities. An important component of these activities is technical use of software for the support of project management and the management of the object, service (or their combination), which are outputs of the project. The important group of the activities creates the management of the cost with the accent on complex project efficiency. The next activities are connected with the management of the processes in the time, their coordination and their following communication among various participants of the project. There are many specialized activities in the life-cycle of the project, and for this reason the project manager must have a broad and complex area of special knowledge. He should improve not only in the area of his competences and skills but also in the area in which he works (in various economic areas or in the security area).

\section{Introduction}

Today, the project has become a standard part of our lives. The projects are realized for example in research, construction area and in services. People understand a design and project as some graphical forms which represent certain situations. Today we understand a design, project activities and project in a different way. The design includes many complex activities which are connected by the project preparation, realization, working and assessment.

\section{Concept Definition of Project}

Today people understand the project as a process of planning and management of big operations. We can see not only the result - project documentation - but also the creative process. There are many definitions of the "project". These definitions can be reduced to the following:

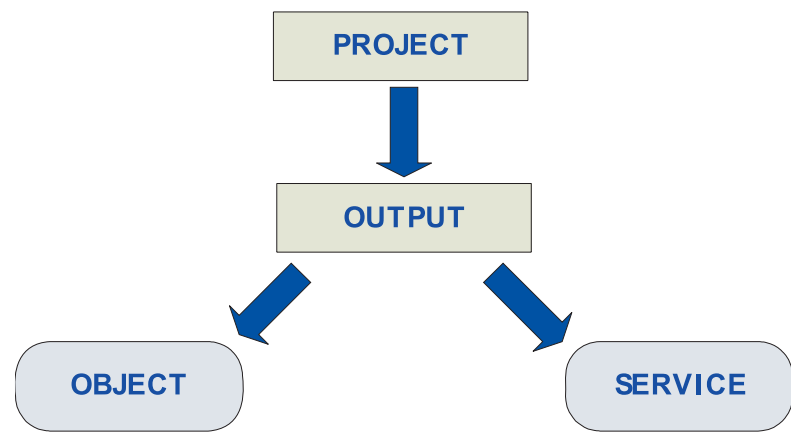

Fig. 1 Output of the project
The project is the systematic suggestion for the realization of definite innovation with the period of beginning and completion, the innovation with regards to time limit, realization of the output, costs and quality [1]

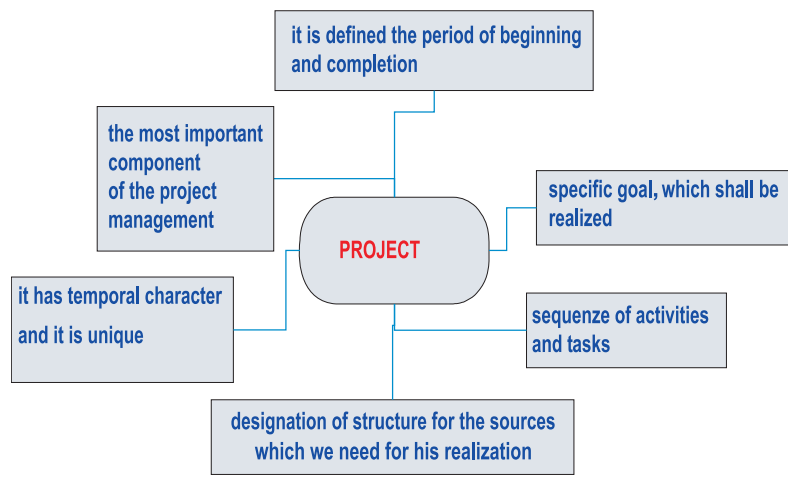

Fig. 2 Characteristics of the project

Every project is unique and this quality is managed with the monitoring of defined goals and with the concreteness of the conditions and environment in which is realized.

\section{Categories and types of projects}

The projects will be different due to the existence of all these presented characteristics not only in terms of extent, cost and time, but also in terms of its content. This is the reason for classification and categorization of projects according to their type.

\footnotetext{
* Josef Reitspis, Gabriela Kormancova

Department of Security Management, Faculty of Special Engineering, University of Žilina, Slovakia, E-mail: josef.reitspis@fsi.uniza.sk
} 


\subsection{Categories of projects}

- complex: a long-time, unique project with a special organizational structure, this project includes many activities,

- special: an intermediate-time project, this project includes fewer activities requiring temporary additional staff,

- simple: a little project, which is realized in a short period, limited number of activities, and requires a limited number of staff.

\subsection{Types of projects}

- building projects: all types of projects, their goal is a new construction or reconstruction of an existing object,

- research and development projects: projects of strategic importance, which provide innovation in different economic areas,

- technological projects: projects which include new technologies to secure production effects (optimalization of technological and material flow, reserves detecting, etc.) and these projects bring the effects of time and space structure into production,

- organization projects: these projects include the change of existing structures [2].

\section{Organization structure of project}

The quality of project management depends mostly on people who are holders of the quality. It depends not only on their individual ambition but also on activities of the whole project team. The members of project team follow defined goals.

There are many interest groups involved in the realization of the project. Every group follows its own individual or group goals. The task of project manager's focus is the harmonization of individual and group goals with the project goals. These things are necessary for successful project achievement.

There are many subjects participating in the project (see Fig. 3).

\subsection{Basic tasks project team members}

Project sponsor - mostly managers of the company,

Project control - accredited member of the managers, responsible for the projects and is their coordinator at the same time,

Expert team - a group of experts, they co-operate with managers, who show interest in the project assignment and evaluate the process of steps, utilization of disposable sources, and effects of the project entry,

Contractors - they deliver products, work or services,

Managers of the project teams - they are responsible for the work of the project team (working on the subprojects),

Project manager - the key person creating the project planning, deciding about special positions in the project, coordinating various tasks from the beginning to completion and transfering outputs to the customer and its following administrative completion [4].

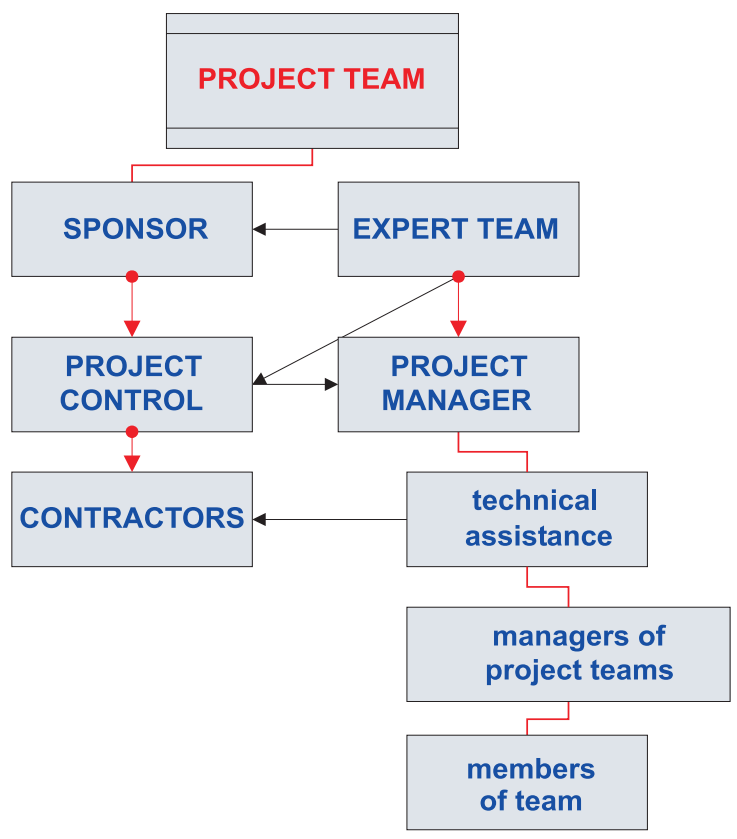

Fig. 3 Structure of the project team

\section{Security systems design}

The methodology of the design in the area of security systems is not defined as expressly as in the other areas (engineering, electrical engineering, building industry, etc.).

The design of security systems can consist of the following steps:

- risk analysis: includes analysis of the security environment, risk identification, their classification, assessment and priority,

- simulation: consists, for example, of simulation of functional behavior in selected parts of the security system,

- construction (designing): schematic design of components in security system with the use the location symbols,

- optimization: effective harmonization of various components in the security system,

- verification of designed security system,

- project of security system,

- validation of security system.

\section{Software tools of design}

The functioning of modern production, systems, and technological operations is not possible without consistent automation of preparation, production and monitor stages during the whole process. We use various software tools by the project management, which are very helpful during the project creation and they make work for the whole project team easier.

These tools are used mostly by projects of a great extent, where they have an irreplaceable task. The realization of the project 
would not be possible without them or it would be realized with problems. The mostly used software tool in this area is MS Project (Fig. 4).

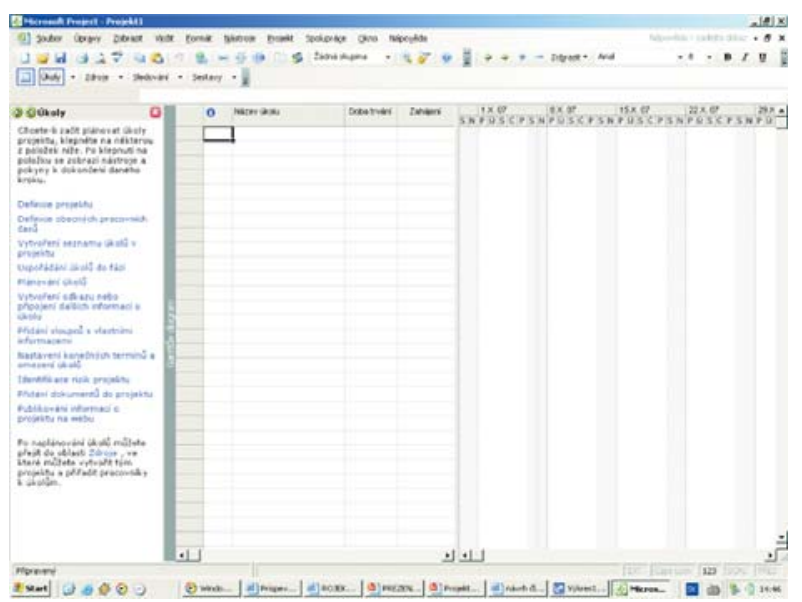

Fig. 4 Working environment of MS Project

Not only we can create completely new projects, but also it is possible to use "model projects" (templates). Advantages of this program are invaluable mainly for projects of a great extent.

When creating projects we can use the MS Visio software (Fig. 5). It creates simple drawings, schemata and also planning of simple tasks in the project.

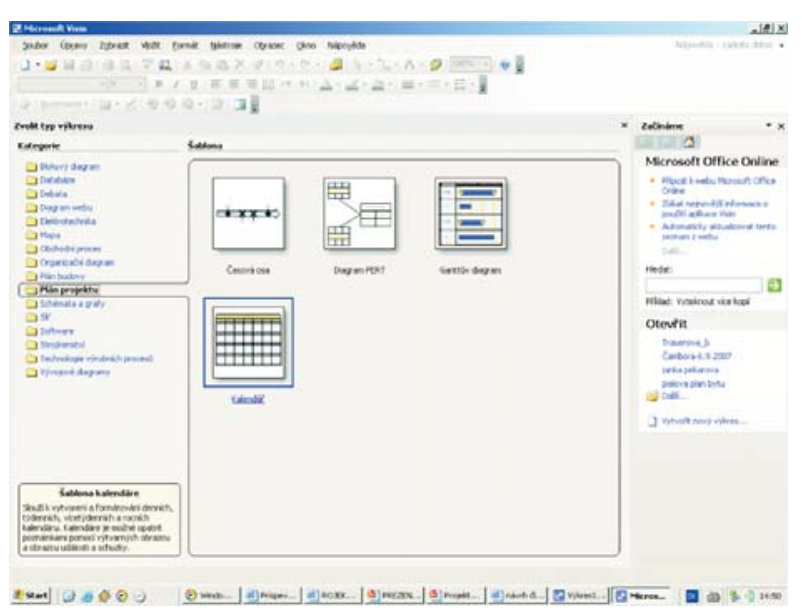

Fig. 5 Structuring of the categories in MS Visio

This program consists of various categories which include some relevant templates. It is comprehensible for a common user as well and sufficient for a projects of lesser extent.

The software tools named CAD (Computer Aided Design) is also used, for example the AutoCAD program. A big group of users apply this program when creating a project documentation including creation of space models. The advantage of this system is especially its exactness, saving of existing data, and the fact that we can create data bases for the using and creating various project documentation [3]. AutoCAD (Fig. 6) is the mostly used graphical system in the world. It offers a whole file of tools for 2D and $3 \mathrm{D}$ construction including the surface and dimensional simulation. It consists of various modules which make use of application program languages real. These application programs are adapted to the conditions of the local technical environment. It is important to use all professional tools for designing.

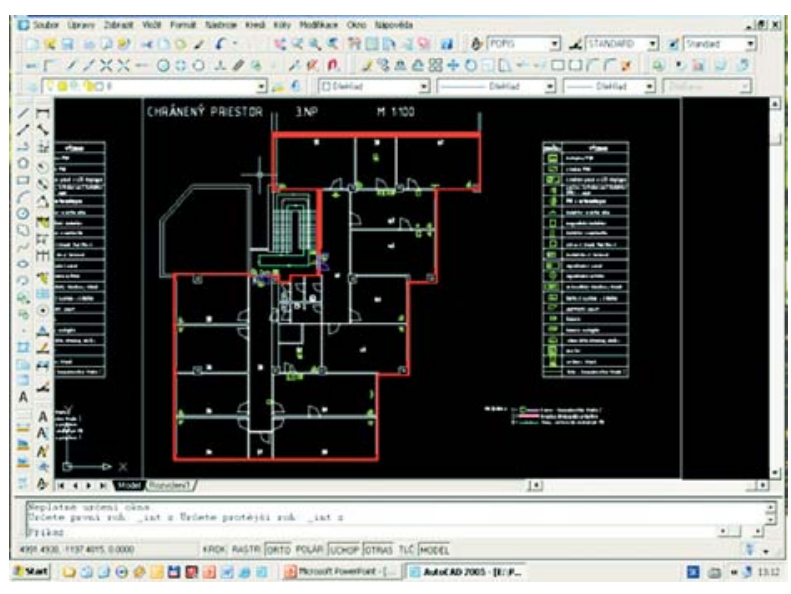

Fig. 6 Working environment of AutoCAD

There are also many others programs which can be used for the design of the security systems. One of the CAD programs which can be used in the security area is for example Video Cad (Fig. 7).

This software makes possible the design and correct location of security cameras in the space for their correct function and effective utilization, especially with reference to the requirements of customer.

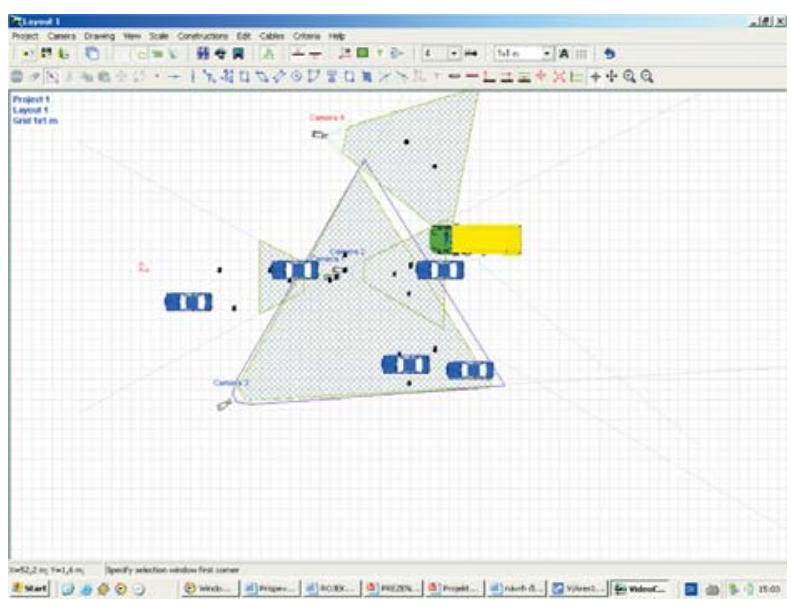

Fig. 7 Working environment of VideoCAD 
7. Conclusion

The presented software tools are possible to use in the area of security systems design. In the future it is necessary to integrate all the project phases of the security systems design with the utilization of acquired experiences. At the same time it is important to define the methodical principles, basic process, management, control and responsibility for the realization of a security project.

\section{References}

[1] NEMEC, V.: Project management (in Czech), GRADA Publishing, Praha 2000.

[2] ROSENAU, M.D.: Operation of projects (in Czech), Computer Press, Praha 2000.

[3] FORT, P., KLETECKA, J.: A utoCAD 14, Computer Press, Praha 1998.

[4] LOVECEK, T., REITSPIS, J.: Designing of security projects, Proc.: 1. medzinarodna vedecko-praktickej konferencia Bezpecnost zivota ludí, ako podmienka staleho rozvoja sucasnej spolocnosti, Lvov, 2005, ISBN 966-699-131-4.

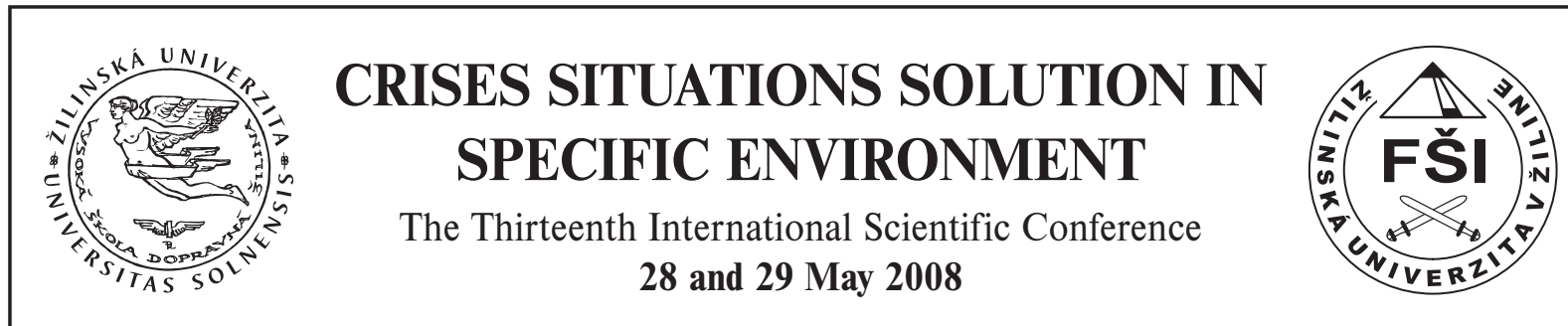

We would like to inform you that the Faculty of Special Engineering of the University of Zilina is organizing an international scientific conference called Crisis Situations Solution in Specific Environment.

The goal of the conference is to exchange the latest findings and practical experience of crisis management, persons and property protection and the tasks of human factors in crises situations.

\section{Conference sections:}

Section No.1: Crisis Management and National Security Section No.2: Security management - people and property protection Section No.3: Solution of Economical Crises Section No.4: Human factor in crisis management Section No.5: Transport in Crisis Situations 